\title{
Report on the first year of applying initial assessment of nutritional status in hospital inpatients
}

\begin{abstract}
Introduction. Since 2012, Polish hospitals are recommended to implement the assessment of the nutritional status and appoint nutrition support teams.

Aim. To evaluate the application of initial assessment of inpatients' nutritional status in the first year of its implementation in clinical practice.

Material and methods. A retrospective analysis of medical documentation of patients admitted to hospital in the year 2012 was conducted. The research sample included one in ten medical records.

Results. A total of 433 medical records was analyzed. In 5.3\% medical records a lack of duly completed Subjective Global Assessment questionnaires was revealed. In 81.8\% cases a calculated Body Mass Index (BMI) was not found. No instances of renewed calculation of BMI were recorded. In $49.7 \%$ cases no information on diet recommended to the inpatient was found. With the exception of the internal medicine ward, in $87 \%$ of the cases the diets were not recommended in writing by a physician or included in the medical orders documentation. The inpatients classified as undernourished were usually recommended a diet containing $2000 \mathrm{kcal}+$ additional $300 \mathrm{kcal}$ as second breakfast and afternoon snack. Information on cooperation with the nutrition support team and on inpatient's nutrition was not included in the nursing documentation.

Conclusions. During the first year when the obligatory patient nutritional status assessment was introduced in Polish hospitals, the awareness of its significance, nutritional therapy planning and monitoring of the results were insufficient. The assessment of nutritional status seems to be another dead letter in patient medical documentation.
\end{abstract}

Keywords: Body Mass Index, diet, malnutrition, screening, Subjective Global Assessment.

DOI: $10.1515 /$ pjph-2015-0057

\section{INTRODUCTION}

Malnutrition is usually defined as a measurable adverse effect of deficiency or excess of energy, protein and other nutrients affecting the way one's body looks and functions [1].

The disorders, both undernutrition and overnutrition, have become a pressing public health problem of the $21^{\text {st }}$ century. They are associated with an increased risk of disease incidence and disease complications, impaired wound healing, longer hospital stays and, consequently, the costs of medical treatment increase $[1,2]$.

Recognizing malnutrition among inpatients, implementation of proper clinical nutrition and monitoring the results of such actions should be one of the standards of daily clinical practice [3]. The resolution issued by Council of Europe ResAP(2003)3, concerning food and nutritional care in hospitals, points to the necessity of preventing disease-related undernutrition by standardizing and providing quality nutritional care as well as by considering patient nutrition to be a form of treatment [4]. Even though Poland has not signed the resolution, since 2012 every patient admitted to a medical care unit (with the exception of hospital emergency department) has undergone assessment of nutritional status according to guidelines defined in "Standards of Parenteral and Enteral Nutrition" (also known as "Standards of Nutritional Therapy") published by Polish Society for Parenteral, Enteral Nutrition and Metabolism (POLSPEN). Inpatients at increased nutritional risk should undergo closer nutritional assessment, including evaluation of functional capacity, mental condition and metabolic status, anamnesis and laboratory tests [5].

Hospitals and other medical and social care centers were advised to implement nutritional status assessment and to appoint nutrition support teams. However, numerous studies show that healthcare professionals still are not aware enough about the importance of nutritional therapy among healthcare professionals. Therefore, the obligatory initial assessment often remains a dead letter in medical records and is not put into practice [5].

\section{AIM}

The purpose of this study was to evaluate the application of initial assessment of inpatients' nutritional status in the accredited Railway Hospital in Wilkowice-Bystra (southern Poland) during the first year of its implementation in clinical practice. 


\section{MATERIAL AND METHODS}

The authors conducted a retrospective analysis of medical documentation of patients admitted to the Railway Hospital in Wilkowice-Bystra (Poland) in 2012. The research sample included one in ten medical records. In each case the Subjective Global Assessment (SGA) questionnaire, documentation concerning implementation of a prospective nutritional therapy, further monitoring of nutritional status and inclusion of nutritional status information (undernutrition or overnutrition) into the nurses' documentation or discharge documentation were analyzed.

The data mentioned above were analyzed and verified statistically using Statistica software (version 10.0). Quantitative features were presented using the arithmetic mean and standard deviation. The Chi-squared test was used to assess the differences between the groups of independent variables. P-values below 0.05 were considered significant.

\section{RESULTS}

A total of 433 medical records were analyzed. The study group characteristics were shown in Table 1 . The analysis of $23(5.3 \%)$ medical records revealed lack of duly completed SGA questionnaires, including only $6(1.4 \%)$ cases justified by the inpatient's condition which made it impossible to examine the patient or take patient's history. Some statistically significant differences were found between the investigated wards and the absence of SGA questionnaires or SGA questionnaires

TABLE 1. Characteristics of the study sample.

\begin{tabular}{lc}
\hline \multicolumn{1}{c}{ Characteristic } & N (\%), mean \pm s.d. (min.-max.) \\
$\mathbf{N}=\mathbf{4 3 3}$
\end{tabular}

that had been improperly filled out $(p=0.02)$. The largest number of SGA irregularities were recorded in the cardiology ward $-10(11.5 \%)$ and neurology rehabilitation ward - $2(7.7 \%)$.

According to data included in the completed SGA questionnaires, 355 persons $(86.6 \%)$ were classified into the SGA A group (well nourished), 19 persons (4.6\%) into the SGA B group (mildly to moderately malnourished), and 6 persons (1.5\%) into the SGA C group (severely malnourished). The remaining 30 participants $(7.3 \%)$ were not classified into any particular SGA group, however their nutritional status was described as "obesity" at the end of the questionnaire. A detailed analysis of documentation of the SGA B and SGA C inpatients with a view to implementing a nutritional therapy revealed that the inpatients classified into both groups were normally recommended a diet containing $2000 \mathrm{kcal}+$ additional $300 \mathrm{kcal}$ as second breakfast and afternoon snack. Only in 6 cases (24\%) committee on nutrition placed supplementary comments under the SGA questionnaire, for example, information on food preference obtained from the inpatient, contacting ward personnel with regard to eating habits and tolerating diet by the inpatient, prospective diet correction or preparation of dietary guidelines for the inpatient to take home. Information on cooperation with the nutrition support team and on inpatient's nutrition was not included in the nursing documentation. Only one case of including information about inpatient's nutritional status (severe malnutrition) in discharge documents was recorded.

An analysis of the SGA questionnaires revealed that doctors conducting the examination of patients suffering from illnesses related to an increase in calorie requirements were most likely to choose the answer suggesting no increase. This is also true for conditions like cancer $(p<0.001)$ or pressure ulcers $(\mathrm{p}=0.03)$. An increase in calorie requirements was neither recommended to any inpatients with overactive thyroid gland, dementia or Parkinson's disease.

Shortcomings were also observed in the part of the SGA questionnaire concerning inpatients' physical capacity. Changes were indicated in case of some 40 inpatients $(9.2 \%)$, however their duration ( $6.6 \pm 6.3$ weeks) was defined only in 35 instances. The type of inpatient's physical capacity (restricted activity, walking, lying) was defined only for $82(20 \%)$ inpatients.

In $354(81.8 \%)$ cases a calculated BMI was not found in the analyzed records, in $50(11.5 \%)$ cases it could not be calculated due to the patients' status, and in $29(6.7 \%)$ cases BMI was calculated and included in the documentation. Significantly, BMI was more frequently calculated for inpatients with firstdegree obesity $(\mathrm{p}<0.01)$. No instances of renewed calculation

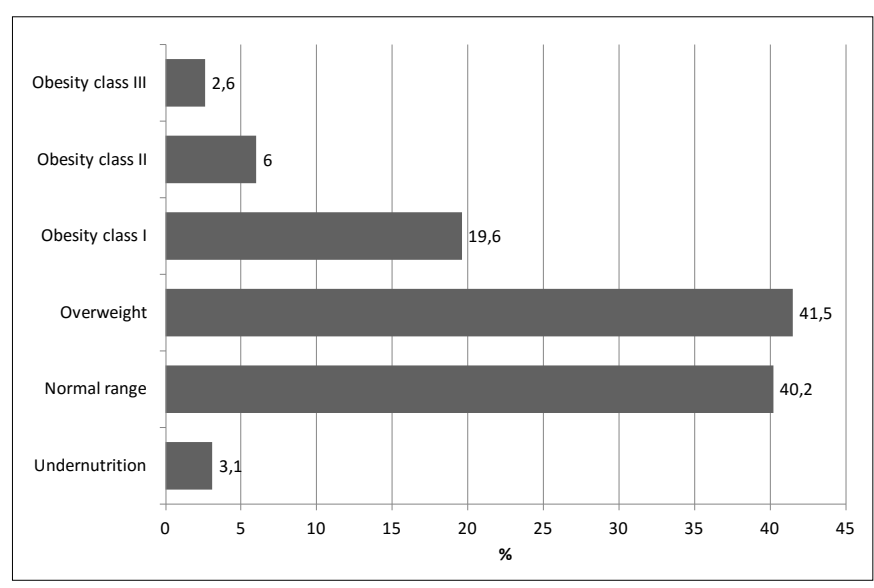

FIGURE 1. Characteristics of the study sample. 
of BMI were recorded, nor were the BMI calculations completed before termination of hospitalization. Categorization of inpatients on the basis of calculations performed during the study made with reference to BMI ranges established by WHO was shown in Figure 1.

In 215 (49.7\%) cases no information on diet recommended to the inpatient was found in the analyzed documentation. Diets recommended in the remaining cases are shown in Table 2. Correlation between the investigated ward and the lack of recommended diet proved to be statistically significant $(p<0.001)$. The lack of recommended diet was most frequently noted in the neurology $-80(83.3 \%)$ and cardiology - $61(70.1 \%)$ wards, and the least frequently - in internal medicine ward -4 (4.2\%). With the exception of the internal medicine ward, in $87 \%$ of the cases doctors did not issue any written recommendation concerning these diets.

TABLE 2. Diets ordered in the study sample.

\begin{tabular}{|c|c|}
\hline Diets & $\begin{array}{l}N(\%) \\
N=218\end{array}$ \\
\hline soft diet & $104(47.7)$ \\
\hline diabetic diet & $85(39)$ \\
\hline low-protein diet & $1(0.5)$ \\
\hline high-protein diet & $4(1.8)$ \\
\hline fat-restricted diet & $5(2.3)$ \\
\hline salt free diet & $2(0.9)$ \\
\hline gluten-free diet & $3(1.4)$ \\
\hline vega diet & $1(0.5)$ \\
\hline liquid diet & $3(1.4)$ \\
\hline mushy foods & $1(0.5)$ \\
\hline nothing by mounth & $1(0.5)$ \\
\hline extra beverages & $3(1.4)$ \\
\hline extra salted food & $5(2.3)$ \\
\hline
\end{tabular}

\section{DISCUSSION}

Nutritional therapy as treatment equal to other forms of curing patients is gaining increased recognition worldwide. However, there are still many obstacles preventing the popularization of such a form of treatment. They include the most serious barriers, such as lack of sufficient knowledge of nutritional therapy or lack of time and staff responsible for nutritional therapy. Yet, when compared to what happened in the past, the so called "nutritional awareness" has considerably increased $[4,6]$.

Apparently, introducing obligatory assessment of inpatient nutritional status in Polish hospitals was also a quantum leap forward for raising awareness of the role which good nutritional status plays in the patients' treatment and convalescent phase. However, in too many healthcare centers the assessment is considered to be just another obligation imposed on employees or just another document to be filled out and attached to medical records. Even though all the steps are included, like appointing the staff responsible for completing the recommended questionnaires or even nutrition support teams are created, healthcare professionals have no idea of any further activities concerning inpatients. The staff conducting initial assessment usually has no knowledge of types and possibilities of nutritional therapy. Plus to that, they often try to avoid noticing eating disorders, so as to avoid "further problems" as well as adding more costs that the hospital has to cover. This problem is not only a Polish phenomenon. Since 2006, in the UK every inpatient has undergone nutritional screening, and inpatients with diagnosed malnutrition or risk of malnutrition have undergone detailed nutritional assessment. In the study conducted by Lamb et al. only $45.2 \%$ of patients with high risk of malnutrition diagnosed at the admission to hospital underwent detailed nutritional assessment and in the case of over $40 \%$ inpatients no further steps were taken [7]. The results of research conducted by Singh at al. also proved that documentation of inpatient nutritional status was insufficient, nutritional intervention was carried out in very few cases despite the fact that prevalence of malnutrition in this population was estimated as high as $69 \%$ [8].

In the present study the level of mild or severe malnutrition is estimated according to SGA scale at $6.1 \%$ of the studied population. However, it has to be assumed that the level of malnutrition might increase during the hospital stay. Malnutrition related to illness is a serious clinical problem [9]. According to the literature, malnutrition develops in $30 \%$ of well-nourished inpatients and increases in as much as $70 \%$ of inpatients malnourished at the moment of admission to hospital $[9,10]$.

A frequent cause of malnutrition in healthcare institutions is the iatrogenic component. It might refer to the lack of appropriate nursing and care (patients who are lying in bed, are weak, cannot eat on their own), starvation during diagnostic tests and the perioperative period, intravenous application of $0,9 \%$ saline and $5 \%$ dextrose for the period longer than 7 days, hospital diet with unknown contents of nutrients and energy $[11,12]$. Lack of interest in nutritional therapy and the fact that provision of meals is perceived by physicians and hospital administration as a hotel service rather than an element of treatment is not without significance either [13].

In Poland, the POLSPEN society recommended NRS 2002 or SGA questionnaires to be used for initial assessment of adult inpatients' nutritional status. Apparently, out of the two research tools only the NRS 2002 questionnaire can be used for nutritional screening. The SGA questionnaire, despite being one of the best contemporary research tools for assessing nutritional status, was created in order to perform detailed nutritional assessment and requires specific clinical skills, inter alia, physical examination and symptom evaluation [14]. However, some authors claim that it can also be used for screening and in the hospital in question it was used for such purposes. It seems that the physicians who conducted assessment, despite their undoubtedly highly specialized clinical skills, were not sufficiently prepared to understand the significance of nutritional therapy as an element of holistic approach to patients. This observation can be made since the evaluation of the increase in calorie requirements in particular disease entities, whose pathological mechanism is clearly related to such changes, was not conducted properly [15]. Apart from filling out the SGA questionnaire, the personnel directly engaged in treatment and nursing did not add any comments on inpatients' nutrition to the medical record. It is emphasized in a number of literary sources that physicians do not feel comfortable discussing patients' nutrition, however, it seems that in such cases the hospital dietician should be the most competent and well prepared person to provide physicians, nurses, inpatients' families and inpatients with advice [15]. Even the best of tools 
for screening or detailed assessment will not fulfill its function if its use is not followed by further activities. According to ESPEN guidelines for nutritional assessment, the next step following classifying patients to a risk group should consist in determining goals, a plan of action (including possible revision in case of low tolerance for nutritional therapy by the patient) and monitoring the results (for example, by recording the amount of food intake, fluid balance, body weight) [3]. According to Polish standards, it is also evident that nutritional assessment and further phases of treatment should take into account all psychosocial and socioeconomic factors which might influence the patients' nutritional habits (for example, individual - ethnic or religious dietetic constraints, family influence, probability of survival, affordability). Information about these factors should be found in medical record [12]. Research conducted within the framework of the present study revealed only few instances of completing the questionnaire with information on application of high calorie diet by the head of a nutrition support team (hospital dietician). However, the recommendation was not individualized and was indeed the same for all inpatients classified into the SGA B and SGA C groups. The ESPEN guidelines also emphasize the role of appropriate communication with patients and conveying the "nutritional" information [3]. However, research has shown that crucial discharge information, related to patient treatment or illness is often incomplete, unclear, or even missed [15]. In this study information on patient nutritional status was included in patient discharge document only in one case. It can suggest that the continuity of care at hospital discharge was not guaranteed.

Calculating inpatients' BMI is not an obligatory element of patient nutritional status assessment, yet it is the simplest and the most widely available tool which can be used in clinical practice. Within this study, BMI was calculated only in few cases and there is no instance of repeating the BMI calculation before the hospitalization was terminated. Having considered the fact that in the analyzed population malnutrition is a less serious problem than overweight and obesity, the BMI calculation could be a helpful element of planning medical treatment (including diet) and nursing care plan. However, in half of the studied cases dietetic treatment was not recommended at all and a significant number of recommended diets was not included in daily medication logs.

\section{CONCLUSIONS}

Summarizing the results of this study, it might be concluded that during the first year of applying obligatory assessment of patient nutritional status, the awareness of its significance proved insufficient. Also, staff knowledge about how to conduct the assessment properly or how to plan various forms of nutritional therapy and monitoring the results were poor. The staff dealing with the assessment of inpatient nutritional status, treatment and nursing should be educated in this respect. Otherwise, it might become another dead record in medical records.

\section{REFERENCES}

1. Jarosz M, Respondek W. Wpływ stanu odżywienia na skuteczność i koszty leczenia. In: M. Jarosz (ed). Zasady prawidłowego żywienia chorych w szpitalach. Warszawa: Instytut Żywności i Żywienia; 2011. p. 26-31.

2. Freijer K, Tan SS, Koopmanschap MA, et al. The economic costs of disease related malnutrition. Clin Nutr. 2013;32:136-41.

3. Kondrup J, Allison SP, Elia M, et al. ESPEN guidelines for nutrition screening 2002. Clin Nutr. 2003;22:415-21.

4. Lindorff-Larsen K, Rasmussen HH, Kondrup J, et al. The Scandinavian Nutrition Group. Management and perception of hospital undernutrition - a positive change among Danish doctors and nurses. Clin Nutr. 2007;26:371-8.

5. Szczygieł B. Leczenie żywieniowe - postępy 2011. Med Prakt Chir. 2012;3:25-31.

6. Hamirudin $\mathrm{AH}$, Charlton $\mathrm{K}$, Walton $\mathrm{K}$, et al. 'We are all time poor' - is routine nutrition screening of older patients feasible? Aust Fam Physician. 2013;42:321-6.

7. Lamb CA, Parr J, Lamb EIM, Warren MD. Adult malnutrition screening, prevalence and management in a United Kingdom hospital: cross-sectional study. Brit J Nutr. 2009;102:571-5.

8. Singh H, Watt K, Veitch R, et al. Malnutrition is prevalent in hospitalized medical patients: are housestaff identifying the malnourished patient? $\mathrm{Nu}$ trition 2006;22:350-4.

9. Naithani S, Thomas JE, Whelan K, Morgan M, Gulliford MC. Experiences of food access in hospital. A new questionnaire measure. Clin Nutr. 2009;28:625-30.

10. Agarwal E, Ferguson M, Banks M, et al. Nutritional status and dietary intake of acute care patients: results from the Nutrition Care Day Survey 2010. Clin Nutr. 2012;31:41-7.

11. Pertkiewicz M. Niedożywienie i jego następstwa. Post Żyw Klin. 2008;2:4-8.

12. Detsky AS, McLaughlin JR, Baker JP, et al. What is subjective global assessment of nutritional status? J Parenter Enteral Nutr. 1987;11:8-13.

13. Kyle UG, Kossovsky MP, Karsegard VL, Pichard C. Comparison of tools for nutritional assessment and screening at hospital admission: a population study. Clin Nutr. 2006;25:409-17.

14. Poulia KA, Yannakoulia M, Karageorgou D, et al. Evaluation of the efficacy of six nutritional screening tools to predict malnutrition in the elderly. Clin Nutr. 2012;31:378-85.

15. Hesselink G, Schoonhoven L, Plas M, et al. Quallity and safety of hospital discharge: a study on experiences and perceptions of patients, relatives and care providers. Int J Quality Health Care. 2013;25:6-74.

\section{Corresponding author}

Beata Babiarczyk

Faculty of Health Sciences, University of Bielsko-Biala

2 Willowa Str, 43-309 Bielsko-Biala, Poland

tel.: +48338279198

E-mail: bbabiarczyk@ath.bielsko.pl 